\title{
Layanan Infrastruktur Komputasi Multitenant dengan OpenStack di Lingkungan MaaS
}

\author{
Joan Ricard Panggabean, Agung Budi Prasetijo, Eko Didik Widianto*) \\ Departemen Teknik Sistem Komputer, Fakultas Teknik, Universitas Diponegoro \\ Jl. Prof. Soedarto, SH, Kampus Undip Tembalang, Semarang, Indonesia 50275
}

Cara sitasi: J. R. Panggabean, A. B. Prasetijo, and E. D. Widianto, "Layanan Infrastruktur Komputasi Multitenant dengan OpenStack di Lingkungan MaaS," Jurnal Teknologi dan Sistem Komputer, vol. 5, no. 4, pp. 142-146, Okt. 2017. doi: 10.14710/jtsiskom.5.4.2017.142-146, [Online].

\begin{abstract}
The growth of high-quality computing needs triggers the development of infrastructure that requires huge costs and resources. This research applied OpenStack in Metal as a Service (MaaS) environment to provide multitenant infrastructure services in the form of virtual machines (IaaS). The capacity of this IaaS system can be configured based on the needs of the computing resources (CPUs, memory, storage, and network interfaces). Users within the tenant can request infrastructure services as their needs without requiring human interaction with each service provider.
\end{abstract}

Keywords - IaaS; infrastructure; Openstack; multitenancy; MaaS

Abstrak - Meningkatnya kebutuhan komputasi
berkualitas tinggi mendorong pengembangan
infrastruktur server yang membutuhkan biaya dan
sumber daya besar. Penelitian ini mengaplikasikan
OpenStack dalam lingkungan Metal as a Service
(MaaS) untuk menyediakan layanan infrastruktur
multitenant berupa mesin-mesin virtual sebagai
Infrastructure as a Service (IaaS). Kapasitas sistem
layanan IaaS ini dapat dikonfigurasi berdasarkan
kebutuhan sumber daya komputasi (CPU, memori,
ruang penyimpan, dan antarmuka jaringan).
Pengguna dalam tenant dapat meminta layanan
infrastruktur secara mandiri dengan kapasitas
komputasi sesuai yang dibutuhkan. Kata Kunci - IaaS; infrastruktur server; OpenStack; multitenancy ; MaaS

\section{Pendahuluan}

Kebutuhan layanan yang lebih besar terhadap server memerlukan pengembangan infrastruktur yang membutuhkan biaya besar. Pengembangan yang efisien memerlukan sebuah sistem yang mampu mendukung pengembangan sistem tanpa harus membeli server fisik dan yang mampu diubah sesuai kebutuhan. Dengan menggunakan jaringan komputer, layanan infrastruktur komputasi dapat dibangun bersama berbentuk layanan

*) Penulis korespondensi (Eko Didik Widianto) Email: didik@live.undip.ac.id komputasi cloud yang berbasis Infrastructure as a Service (IaaS) [1]. Permasalahan keterbatasan infrastruktur fisik dapat diatasi dengan karakteristik cloud yang mandiri, elastis, cepat dan layanan yang terukur [2].

IaaS menyediakan infrastruktur server sebagai sebuah layanan secara lebih efisien dan elastik [3], [4]. Salah satu platform untuk menyediakan IaaS adalah OpenStack. Nugraha dkk. [5] mengimplementasikan OpenStack untuk membangun layanan IaaS menggunakan dua buah server fisik. Platform lainnya untuk membangun IaaS adalah Ubuntu Enterprise Cloud seperti yang dilakukan Ernawati dan Zulfiaji [6], dan Eucaplyptus seperti yang dilakukan Rahma dkk. [7]. Penelitian-penelitian tersebut dibangun menggunakan beberapa server fisik untuk membangun layanan cloud dan digunakan untuk menghasilkan mesin virtual (IaaS).

Komputasi cloud dan IaaS menyediakan penghematan dalam pengadaan sumber daya/infrastruktur komputasi. Penyedia layanan IaaS mampu memberikan sumber daya komputasi dengan mekanisme multitenant, yang memungkinkan sejumlah sumber daya komputasi digunakan secara bersama-sama oleh beberapa pengguna baik dalam bentuk fisik maupun virtual dan dapat dialokasikan secara dinamis sesuai kebutuhan pengguna [8]. Pengguna IaaS juga dapat melakukan pelayanan mandiri pada tingkatan tenant, seperti pengaturan server dan jaringan, tanpa interaksi dari administrator atau penyedia layanan [9].

Sistem multitenant ini telah diterapkan di layanan Software as a Service (SaaS), seperti dilakukan Herlambang [10] untuk perangkat lunak enterprise resource planning (ERP), Firmansyah [11] untuk perangkat lunak learning content management system (LCMS) dan Fanany [12] untuk perangkat lunak akutansi. Penelitian ini bertujuan untuk menerapkan multitenancy di layanan IaaS untuk memberikan layanan infrastruktur komputasi berupa mesin virtual (VM) untuk sejumlah pengguna di atas infrastruktur fisik yang digunakan bersama dan bersifat dapat digunakan kembali (reusable). Penerapan multitenancy ini akan membuat kebutuhan infrastruktur server suatu tenant dapat terpenuhi sesuai yang diinginkan tanpa mempengaruhi tenant yang lain walaupun diimplementasikan di infrastruktur fisik bersama. 


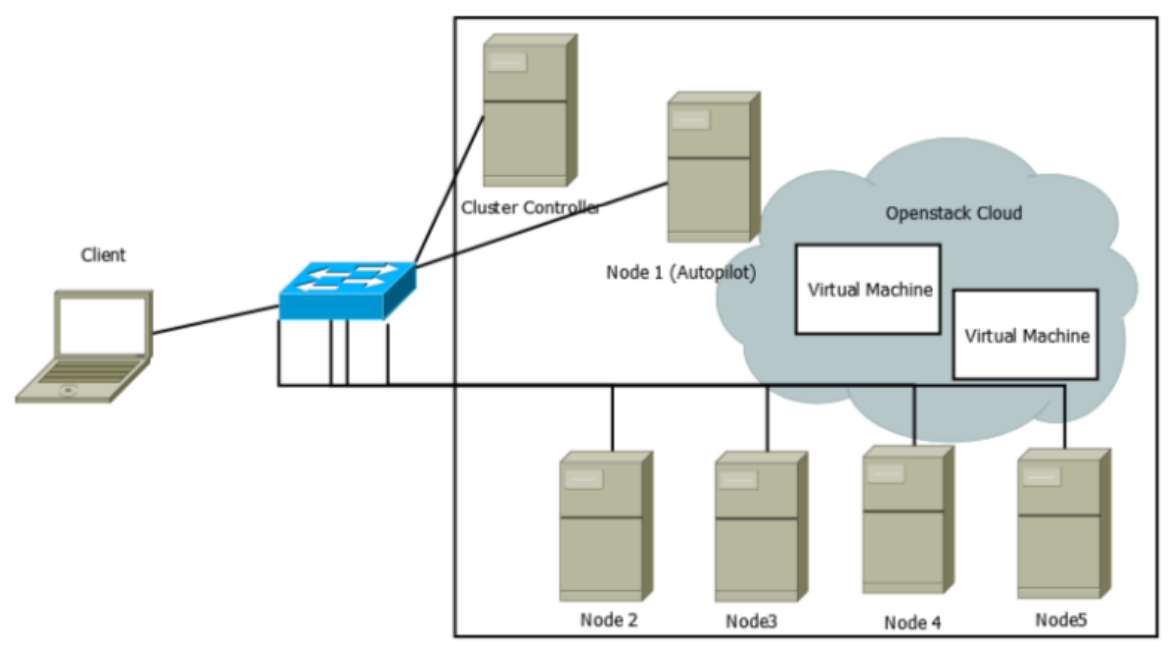

Gambar 1. Layanan infrastruktur komputasi yang akan dibangun

Penyediaan layanan infrastruktur dilakukan dengan menggunakan OpenStack.

\section{Metode Penelitian}

Sistem Layanan IaaS dibangun di atas sumber daya perangkat keras (komputer fisik) dalam lingkungan Metal as A Service (MaaS) menggunakan OpenStack. Perangkat keras yang digunakan dalam penelitian ini adalah 6 (enam) buah server fisik, yaitu satu server untuk klaster MaaS, dan 5 (lima) server sebagai node komputasi, serta 1 (satu) buah perangkat switch Cisco Catalyst 2960. Skema perancangan infrastruktur komputasi ini ditunjukkan dalam Gambar 1. Dari lima node server, satu server digunakan sebagai autopilot, sedangkan empat server lainnya sebagai slave. Semua node server menjalankan semua servis dari OpenStack dan berfungsi sebagai penyedia layanan komputasi untuk membangkitkan VM. Klien digunakan untuk membangun instance dan terhubung ke antarmuka web untuk mengelola sistem layanan IaaS.

Spesifikasi server yang digunakan ditunjukkan dalam Tabel 1. Sistem operasi yang terpasang di klaster MaaS adalah Ubuntu Server 14.04 LTS dan lingkung MaaS, sedangkan di tiap node terpasang Ubuntu Server 14.04 LTS dan OpenStack Autopilot Liberty. Klaster MaaS digunakan untuk mengumpulkan sumber daya yang ada pada node server yang akan digunakan untuk membangun sistem layanan IaaS. OpenStack yang terpasang terdiri dari komponen Nova yang menyediakan sumber daya komputasi (CPU, RAM, ruang penyimpan) dan jaringan, Glance, Keystone, Horizon, dan Swift. Konfigurasi semua perangkat keras dan perangkat lunak dilakukan agar sistem dapat berjalan baik, di antaranya konfigurasi jaringan untuk menghubungkan semua server, instalasi MaaS pada server, konfigurasi klaster MaaS, pendaftaran dan pengawasan node pada klaster MaaS, serta instalasi OpenStack.

Pengujian yang dilakukan adalah secara fungsional untuk menguji mekanisme multitenancy di infrastruktur layanan komputasi. Pembuatan tenant, kapasitas sumber
Tabel 1. Spesifikasi server fisik

\begin{tabular}{lll}
\hline \multirow{2}{*}{ Komponen } & \multicolumn{2}{c}{ Server } \\
\cline { 2 - 3 } & \multicolumn{1}{c}{ MaaS Cluster } & \multicolumn{1}{c}{ Node } \\
\hline Prosesor & Pentium(R) Dual- & Pentium(R) Dual- \\
& Core CPU E2200 @ & Core CPU E6300 @ \\
& $2.20 \mathrm{GHz}$ & $2.80 \mathrm{GHz}$ \\
RAM & $4 \mathrm{~GB}$ & $1,9 \mathrm{~GB}$ \\
HDD & $2 \times 500 \mathrm{~GB}$ & $320 \mathrm{~GB}+$ USB Disk \\
NIC & 2 Fast Ethernet & 2 Fast Ethernet \\
Perangkat & Ubuntu Server 14.04 & Ubuntu Server 14.04 \\
Lunak & LTS dan Metal as a & LTS dan OpenStack \\
& Service & Autopilot Liberty \\
\hline
\end{tabular}

Tabel 2. Spesifikasi perangkat lunak di VM

\begin{tabular}{ll}
\hline Spesifikasi Teknis & Keterangan \\
\hline Sistem operasi & Ubuntu Server 14.04 LTS 64 bit \\
OpenStack & OpenStack Autopilot Liberty \\
Apache & 2.2 .22 \\
Format image & Qcow2 \\
\hline
\end{tabular}

daya (prosesor, memori, penyimpan dan jaringan), otorisasi pengguna sebagai tenant, dan membangkitkan instance atau VM yang sedang berjalan. VM dibangun berdasarkan himpunan flavor atau template VM yang berisi spesifikasi prosesor, memori dan ruang penyimpan). Untuk tiap instance dengan flavor beragam, akan dijalankan sistem operasi dengan spesifikasi seperti ditunjukkan dalam Tabel 2. Konfigurasi instance yang dilakukan meliputi pengaturan hostname dan pengaktifan akses SSH.

\section{Hasil dan Pembahasan}

Infrastruktur yang mampu memberikan layanan komputasi (IaaS) yang multitenancy memerlukan perancangan jaringan yang baik agar dapat dikendalikan dan dikelola dengan efektif oleh penyedia dan pengguna layanan IaaS. Perancangan jaringan dilakukan pada jaringan lokal sehingga infrastruktur IaaS hanya dapat 


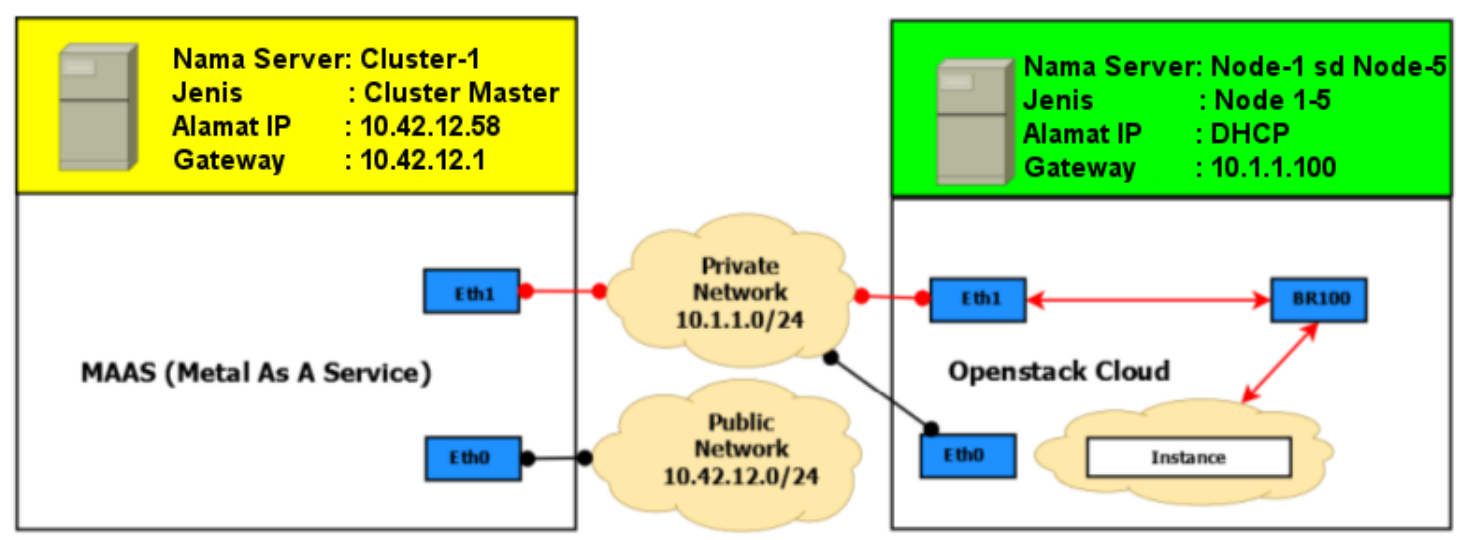

Gambar 2. Skema perancangan jaringan

diakses dari dalam seperti skema yang ditunjukkan pada Gambar 2. Node server yang berperan untuk membangun infrastruktur komputasi bisa berkomunikasi dalam jaringan lokal, namun dapat mengakses jaringan luar melalui antarmuka server Cluster Master. Untuk implementasi yang lebih terbuka, jaringan publik ini dapat diganti dengan alamat publik yang bisa diakses dari Internet.

Klaster MaaS memiliki dua antarmuka jaringan yang masing-masing terhubung pada jaringan lokal Undip dan node server dalam jaringan privat dengan alamat IP statik. Tiap node mempunyai dua antarmuka jaringan yang terhubung ke jaringan privat dengan alamat IP DHCP. Instance (VM) mempunyai dua tipe alamat IP, yaitu IP tetap (fixed IP) dan IP mengambang (floating $I P)$. IP tetap digunakan untuk berkomunikasi antara instance dengan sistem internal layanan IaaS, sedangkan IP mengambang digunakan untuk berkomunikasi dengan jaringan luar dimana semua instance terhubung dengan bridge yang sama. Konfigurasi jaringan klaster MaaS, node server dan VM ditunjukkan dalam Tabel 3, Tabel 4, dan Tabel 5. Konfigurasi tersebut memungkinkan sistem layanan IaaS dapat membangkitkan instance dengan alamat IP mengambang dan instance dapat terhubung dengan jaringan lokal maupun jaringan luar.

Kemampuan sistem layanan IaaS yang multitenant ditunjukkan dengan fungsionalitas sistem tersebut untuk mendaftarkan node ke MaaS, melakukan pengawasan node, pembuatan tenant, pemberian akses tenant kepada pengguna dan manajemen VM oleh pengguna untuk menyediakan infrastruktur komputasi. Node1 sampai Node5 yang akan digunakan untuk membangun sistem layanan didaftarkan dan dikonfigurasi di klaster MaaS. Fitur wake-on-lan dan urutan prioritas boot dari jaringan (network boot) diaktifkan di tiap node. Saat dinyalakan, node akan mendapatkan informasi boot dan boot image dari klaster MaaS dan terdaftar dalam MaaS dengan nama node diberikan dengan dua kata seperti ditunjukkan dalam Gambar 3. Klaster MaaS mendapatkan informasi perangkat keras dari tiap node yang sudah terdaftar (commisioning), meliputi jumlah inti CPU, memori dalam GB, jumlah disk dan kapasitas penyimpanannya. Jumlah node dalam sistem layanan
Tabel 3. Konfigurasi jaringan klaster MaaS

\begin{tabular}{ll}
\hline Spesifikasi Teknis & Keterangan \\
\hline Antarmuka jaringan & Eth0 - Jaringan publik \\
& Eth1 - Jaringan privat \\
Alamat IP & Eth0 - 10.42.12.58/24 \\
& Eth1 - 10.1.1.100/24 \\
Hostname & Cluster-1 \\
Server DNS & 8.8 .8 .8 \\
Alamat gateway & 10.42 .12 .1 \\
\hline
\end{tabular}

Tabel 4. Konfigurasi jaringan untuk node server

\begin{tabular}{ll}
\hline Spesifikasi Teknis & Keterangan \\
\hline Antarmuka jaringan & Eth0 - Jaringan privat \\
& Eth1 - Jaringan privat \\
Alamat IP & Eth0 - DHCP \\
& Eth1 - DHCP \\
Hostname & Node1-Node5 \\
Server DNS & 8.8 .8 .8 \\
Alamat gateway & 10.1 .1 .100 \\
\hline
\end{tabular}

Tabel 5. Konfigurasi jaringan untuk mesin virtual

\begin{tabular}{ll}
\hline Spesifikasi Teknis & Keterangan \\
\hline Antarmuka jaringan & Eth1 \\
Alamat IP & Fixed IP - 10.10.0.1/16 \\
& Floating IP - 10.1.1.0/24 \\
Server DNS & 10.42 .12 .110 .1 .1 .1008 .8 .8 .8 \\
Alamat gateway & 10.1 .1 .10010 .10 .0 .1 \\
\hline
\end{tabular}

dapat dialokasikan secara dinamis sesuai dengan kebutuhan pengelola sistem layanan IaaS [8]. Utilitas sumber daya yang digunakan oleh tenant ditampilkan di halaman informasi ringkas setelah pengguna login ke sistem layanan IaaS seperti ditunjukkan dalam Gambar 4.

Pembuatan tenant dilakukan oleh administrator atau pengelola sistem layanan IaaS. Informasi dalam pembuatan tenant berisi tentang nama dan deskripsi tenant (proyek), pengguna yang diperbolehkan menggunakan tenant (akses) dan kapasitas sumber daya yang bisa digunakan oleh tenant dari yang tersedia di 


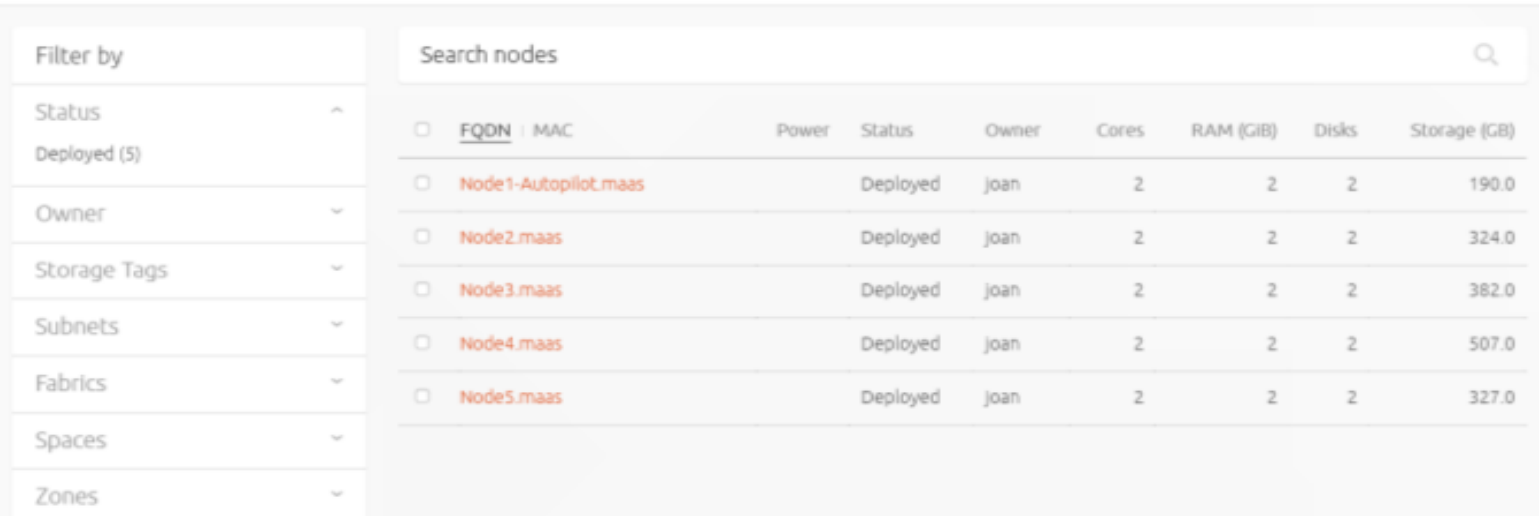

Gambar 3. Node yang telah terdaftar di klaster MaaS

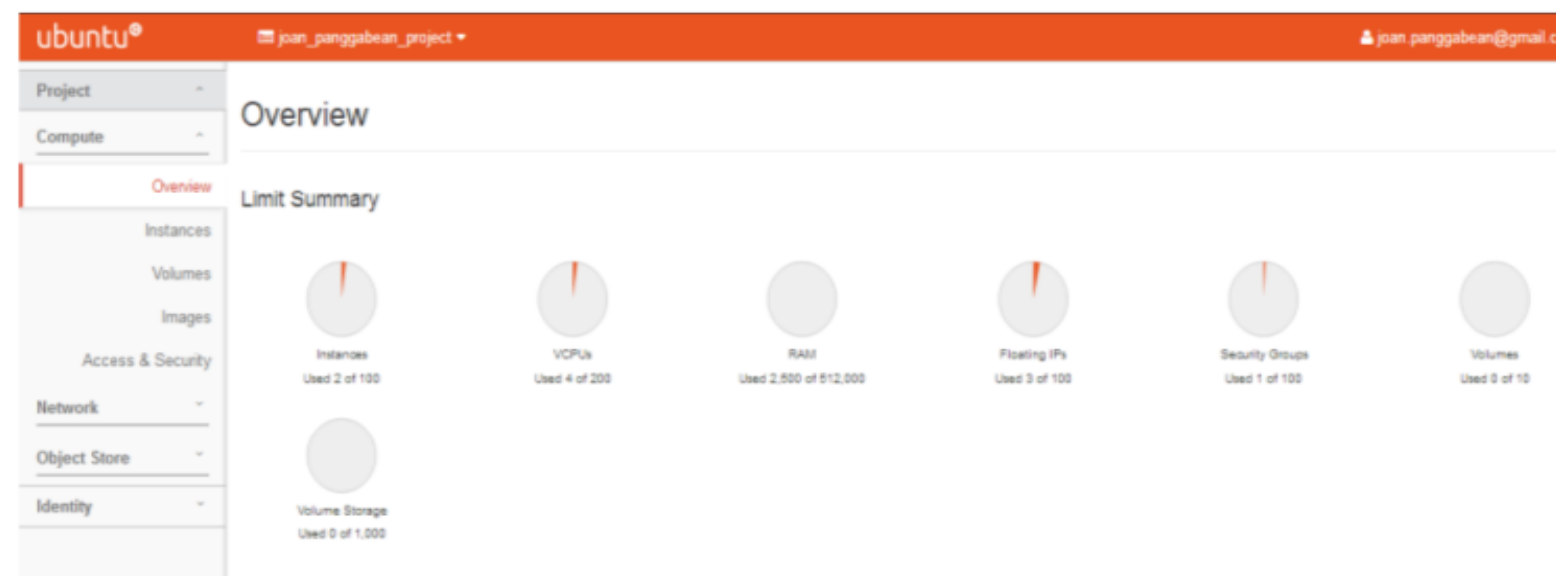

Gambar 4. Tampilan ringkasan informasi tenant dan utilitas sumber dayanya

sistem layanan IaaS (kuota). Kuota yang bisa diatur adalah jumlah virtual CPU, instance yang bisa dibangkitkan, kapasitas RAM dan kapasitas penyimpanan seperti ditunjukkan dalam Gambar 5.

Dalam satu tenant, pengguna dapat memanfaatkan layanan sumber daya komputasi yang disediakan dengan batasan kuota yang telah ditentukan. Jika tenant menggunakan sumber daya yang melebihi kuota, maka sistem layanan IaaS akan memberi peringatan kepada tenant dan tidak melayani permintaan tenant. Pengguna dapat membuat VM dengan memilih OS yang telah disediakan sistem layanan IaaS, flavor yang berisi template VM dan antarmuka jaringan dan konfigurasinya terutama IP mengambang, dan konfigurasi SSH. Template VM memuat jumlah CPU, RAM, dan kapasitas penyimpan yang telah ditentukan sebelumnya oleh administrator tenant. Dengan pemberian IP mengambang, instance dapat terhubung dan diakses dari jaringan publik.

Sistem layanan IaaS tersebut dapat menyediakan layanan infrastruktur komputasi berupa mesin-mesin virtual yang dapat dikonfigurasi kapasitas CPU, memori, ruang penyimpan dan antarmuka jaringan seperti layanan IaaS dalam [5]-[7], namun dengan

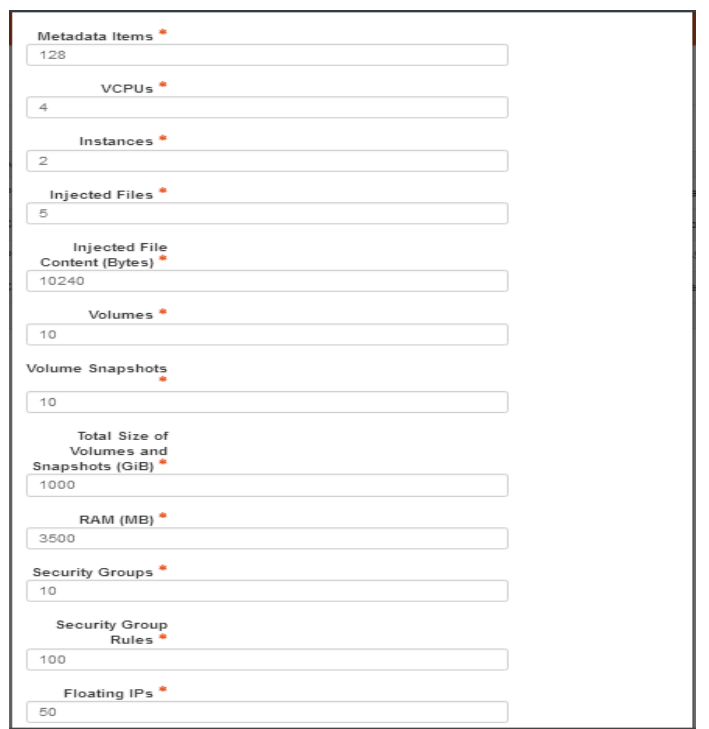

Gambar 5. Pengaturan kuota sumber daya komputasi tenant

kemampuan multitenancy [8]. Tenant yang dibuat tidak mempengaruhi tenant yang lain serta jumlah sumber daya dan instance yang dapat dijalankan terbatas pada 
kuota yang diberikan pada saat pembuatan tenant. Klaster MaaS diimplementasikan untuk manajemen node dalam sistem layanan IaaS. Penambahan dan pengurangan node untuk memenuhi kebutuhan tenant secara dinamis dapat dilakukan sehingga layanan infrastruktur dapat disajikan secara efisien dan elastik [2]-[4], [8]. Pada tingkatan tenant, pengguna dapat melakukan pelayanan mandiri untuk membuat VM, mengkonfigurasi sumber daya komputasi untuk VM dan pengaturan jaringan [9]. Instance yang dibangun dapat mengakses jaringan lokal dan jaringan publik sehingga dapat digunakan untuk menyediakan layanan di layer atasnya, misalnya untuk menyediakan layanan eGoverment berbasis cloud [15]. Perhatian terhadap sisi keamanan dalam sistem multitenant ini perlu dilakukan untuk mengidentifikasi permasalahan keamanan pemakaian sumber daya bersama dan mencari solusinya [8], [16].

\section{KESIMPULAN}

Penyediaan layanan IaaS yang bersifat multitenancy menggunakan OpenStack pada lingkungan MaaS telah dapat berjalan di atas komputer fisik dan disediakan dalam bentuk mesin virtual. Sistem layanan IaaS tersebut telah menyediakan layanan yang menggunakan sumber daya komputasi secara bersama dengan mengalokasikan sumber daya kepada pengguna secara mandiri, dinamis dan sesuai kebutuhan untuk tiap tenant secara bebas.

\section{Daftar Pustaka}

[1] P. Mell and T. Grance, "The NIST Definition of Cloud Computing Recommendations of the National Institute of Standards and Technology," U.S Department of Commerce, 2011. [Online]. http://faculty.winthrop.edu/domanm/csci411/Hand outs/NIST.pdf.

[2] Y. Jadeja and K. Modi, "Cloud computingConcepts, Architecture and Challenges," In 2012 International Conference on Computing, Electronics and Electrical Technologies (ICCEET), pp. 877-880. IEEE, 2012.

[3] L. Youseff, M. Butrico, and D. Da Silva, "Toward a Unified Ontology of Cloud Computing," in Proc. Grid Computing Environments Workshop (GCE08), 2008.

[4] M. Armburst, A. Fox, R. Griffith, A. D. Joseph, R. H. Katz, A. Konwinski, G. Lee, D. A. Patterson, A. Rabkin, I. Stoica, and M. Zaharia, "Above the Clouds: a Berkeley View of Cloud Computing", Technical Report UCB/EECS-2009-28, University of California, Berkeley, 2009.

[5] P. G. S. C. Nugraha, I. K. A. Mogi, and I. M. A.
Setiawan, "Implementasi Private Cloud Computing Sebagai Layanan Infrastructure As A Service (IAAS) Menggunakan Openstack," Jurnal Ilmu Komputer, vol. 8, no. 2, pp. 7-14, September 2015.

[6] T. Ernawati and A. H. Zulfiaji, "Analisis dan Pembangungan Infrastruktur Cloud Computing," Jurnal Cybernatika, vol. 1, no. 2, 2014.

[7] N. F. Rahma, A. F. Rochim, and E. D. Widianto, "Analisis Implementasi Infrastructure As A Service Menggunakan Ubuntu Cloud Infrastruktur," Jurnal Teknologi dan Sistem Komputer, vol. 2, no. 1, pp. 79-86, 2014.

[8] H. Aljahdali, A. Albatli, P. Garraghan, P. Townend, L. Lau, J. Xu, "Multi-Tenancy in Cloud Computing," in Proc. 8th IEEE International Symposium on Service-Oriented System Engineering (SOSE), 7-11 April 2014, Oxford, UK. IEEE, pp. 344-351.

[9] A. Budiyanto, Pengantar Cloud Computing. Komunitas Cloud Computing Indonesia, 2012.

[10] R. W. Herlambang, R. Sarno, and D. Sunaryono, "Implementasi Modul-modul Enterprise Resource Planning Multi Tenant pada Cloud Computing," Jurnal Teknik ITS, vol. 2, no. 1, pp. A183-A188, 2013.

[11] R. A. Firmansyah, "Desain Integrasi Learning Content Management System pada Cloud-base Sistem Informasi Sekolah sebagai Peningkatan Keunggulan Daya Saing," Semnasteknomedia, vol. 1, no. 1, pp. 3-7, 2013.

[12] Z. Fanany, Perancangan Sistem Informasi Akuntansi Multi-Tenant pada Perusahaan Dagang Berbasis Cloud Computing Website dengan Metode Rapid Application Development. Skripsi. Unika Soegijapranata, 2014.

[13] Z. Dimitrios, L. Dimitrios, "Addressing Cloud Computing Security Issues," Future Generation Computer Systems, vol. 28, no. 3, pp. 583-592, March 2012.

[14] R. Kumar, N. Gupta, S. Charu, K. Jain, and S. K. Jangir, "Open Source Solution for Cloud Computing Platform using OpenStack," International Journal of Computer Science and Mobile Computing, vol. 3, no. 5, pp. 89-98, 2014.

[15] E. D. Widianto, "Menuju Sistem e-Goverment Terpadu dan Handal Berbasis Cloud Computing," Jurnal Sistem Komputer, vol. 1, no. 1, pp. 55-59, 2011.

[16] T. Takahashi, G. Blanc, Y. Kadobayashi, D. Fall, H. Hazeyama, and S. I. Matsuo, "Enabling Secure Multitenancy in Cloud Computing: Challenges and Approaches," in 2012 2nd Baltic Congress on Future Internet Communications, pp. 72-79. IEEE, 2012. 